\title{
Domestic gas appliances and lung disease
}

\author{
Anne Fuhlbrigge, Scott Weiss
}

Channing Laboratory, Department of Medicine, Brigham and Women's Hospital, Harvard University, Boston, Massachusetts, USA

Introductory article

\section{Association of respiratory symptoms and lung function in young adults with use of domestic gas appliances}

\section{Jarvis, S Chinn, C Luczynska, P Burney}

Background. There is evidence from some studies that people living in homes with gas stoves and other unvented gas appliances experience more respiratory symptoms than those who use other fuels for cooking and heating, but other studies have found no such association. We have investigated whether the use of gas appliances is associated with an increased risk of respiratory symptoms and whether sensitisation to common environmental allergens modifies any such association. Methods. A stratified random sample of 15000 adults aged 20-44 years, living in three towns in East Anglia, UK, were sent a questionnaire on asthma and hayfever. From those who responded, a random sample of 1864 were invited to complete an extended questionnaire that included questions on use of gas appliances, to give blood samples for measurement of total $\lg \mathrm{E}$ and specific $\lg \mathrm{E}$ to common allergens, and to undergo tests of respiratory function. 659 women and 500 men agreed to an interview. The association of the use of gas appliances with respiratory symptoms, total $\mathrm{lgE}$, specific $\mathrm{lgE}$, and respiratory function was assessed by logistic and multiple regression models. Findings. Women who reported they mainly used gas for cooking had an increased risk of several asthma-like symptoms during the past 12 months including wheeze (odds ratio 2.07 [95\% Cl 1.41-3.05]), waking with shortness of breath (2.32 [1.25-4.34]), and asthma attacks (2.60 [1.20-5.65]). Gas cooking increased the risk of symptoms more in women who were atopic than in non-atopic women but the difference did not reach significance $(p>0.05)$. Women who used a gas stove or had an open gas fire had reduced lung function (forced expiratory volume in $1 \mathrm{~s}\left[\mathrm{FEV}_{1}\right]$ ) and increased airways obstruction (FEV 1 as a percentage of forced vital capacity) compared with women who did not. These associations were not observed in men. Interpretation. In East Anglia, the use of gas cooking is significantly associated with subjective and objective markers of respiratory morbidity in women but not in men. Women may be more susceptible than men to the products of gas combustion or they may have greater exposure to high concentrations of these products because they cook more frequently than men. (Lancet 1996;347:426-31)

The lungs provide the most common site for infections in the United States and other developed countries. ${ }^{1}$ Although the mortality rate is low, respiratory infections can have serious consequences for groups with increased susceptibility (asthma, COPD). The prevalence, morbidity, and mortality of asthma appear to be increasing bidity, and mortality of asthma appear to be increasing in developed countries, 23 and concern about the cause of this increase has drawn attention to environmental
exposures that may be contributing factors.

Susceptibility to respiratory infections is determined by a combination of host and environmental factors The role of indoor pollution has been increasingly recognised. For certain pollutants, the indoor environment is a greater determinant of human exposure than the outdoor environment. Time-activity diaries show that the average person spends approximately 22 hours a day indoors (92\%), the majority of that time at home (16 hours). ${ }^{45}$ As emphasis has been placed on energy conservation, ventilation rates in newer structures have been reduced and winter air exchange rates in newer homes can be as low as $0.1-0.3 /$ houge rates lowered exchange rates, the concentration of indoor lowered exchange rates, the concentration of indoor
pollutants is increased. F or these reasons, research has
been directed towards evaluating an association between respiratory illness and indoor exposures. The introductory article is timely in stimulating further interest in the topic and, in particular, in indoor air pollution associated with gas combustion. 
Indoor air pollutants from gas combustion

The predominant sources of indoor air pollution are combustion products from gas appliances and tobacco smoking. U nvented cooking or heating appliances using gas or kerosene produce a complex mixture including water vapour, carbon monoxide, carbon dioxide, nitric oxide, sulphur dioxide, formaldehyde, carbon particles, and sulphate particles. ${ }^{7}$ T he use of gas appliances leads and sulphate particles. ${ }^{7}$ T he use of gas appliances leads to concentrations of nitrogen oxides that are frequently
higher than those found outdoors ${ }^{8}-$ in $10 \%$ of homes higher than those found outdoors
with gas cooking appliances levels higher than the US $\mathrm{N}$ ational Ambient Air Quality Standard of $100 \mu \mathrm{g} / \mathrm{m}^{3}$ have been documented. ${ }^{9} \mathrm{~T}$ he dominant oxide produced is nitric oxide ( $\mathrm{NO}$ ) which during its atmospheric lifetime, is progressively oxidised to nitrogen dioxide $\left(\mathrm{NO}_{2}\right)$; the potential for adverse health effects is at$\left(\mathrm{NO}_{2}\right)$; the potential for adverse healt
tributed to both of these substances.

tributed to both of these substances.
To date, most of the research has focused on the To date, most of the research has focused on the
effects of $\mathrm{N}_{2}$, which can cause severe lung injury and even death when encountered in high concentrations as illustrated by "silo filler's disease". T he effect of acute exposure to high levels of $\mathrm{NO}_{2}$ has been demonstrated in other occupational settings. Apollo astronauts accidentally exposed to $\mathrm{NO}_{2}(250000 \mathrm{ppb}$ for about four minutes) developed clinical and radiographic evidence of chemical pneumonitis. M easurements of urinary hydroxylysine glycosides indicated possible collagen degradation. ${ }^{10}$

It has become increasingly evident that $\mathrm{NO}$ also has significant effects on the respiratory system as a vasodilator, a neurotransmitter, and an inflammatory mediator in the airways. ${ }^{11}$ While it may have beneficial mediator in the airways. ${ }^{11}$ While it may have beneficial
effects on airway function as a bronchodilator and neurotransmitter of bronchodilator nerves in human airways, NO may also have deleterious effects on the airways by increasing plasma exudation and amplifying and oxidants increase the expression of an inducible form of NO synthase in airway epithelial cells. The impact of indoor N O as a combustion product from gas appliances has not been studied.

DETERMINANTS OF $\mathrm{NO}_{2}$ EXPOSURE

The indoor air concentration of $\mathrm{NO}_{2}$ and other pollutants depends on the indoor source and on dispersion conversion to other compounds, and removal by ventilation. Indoor levels are also influenced by outdoor concentrations and building characteristics. Personal exposure is influenced by time-activity patterns, the amount of time spent indoors, within the home, in various rooms, and in activities that increase exposure Infants spend most of their time sleeping, so the bedroom environment is particularly important. F or young women, who are traditionally responsible for most household cooking, peak exposures occur during cooking. Persons cooking with a gas stove can be exposed to levels of pollutants two orders of magnitude higher $\left(>1000 \mathrm{ppb}\right.$ ) than the average room concentration ${ }^{12}$ The personal health effects are then influenced by host factors including age, sex, coexisting state of health, physiological state (exercising versus resting during exphysiological state (exercising versus resting during ex-
posure), previous exposure history, and personal susposure), previous exposure history, and personal sus-
ceptibility. These pollutants may also interact with other substances in the indoor environment such as allergens, other gases, passive and active smoking. The health effects in an individual are likely to be the result of a complex interaction between all of these factors (fig 1).

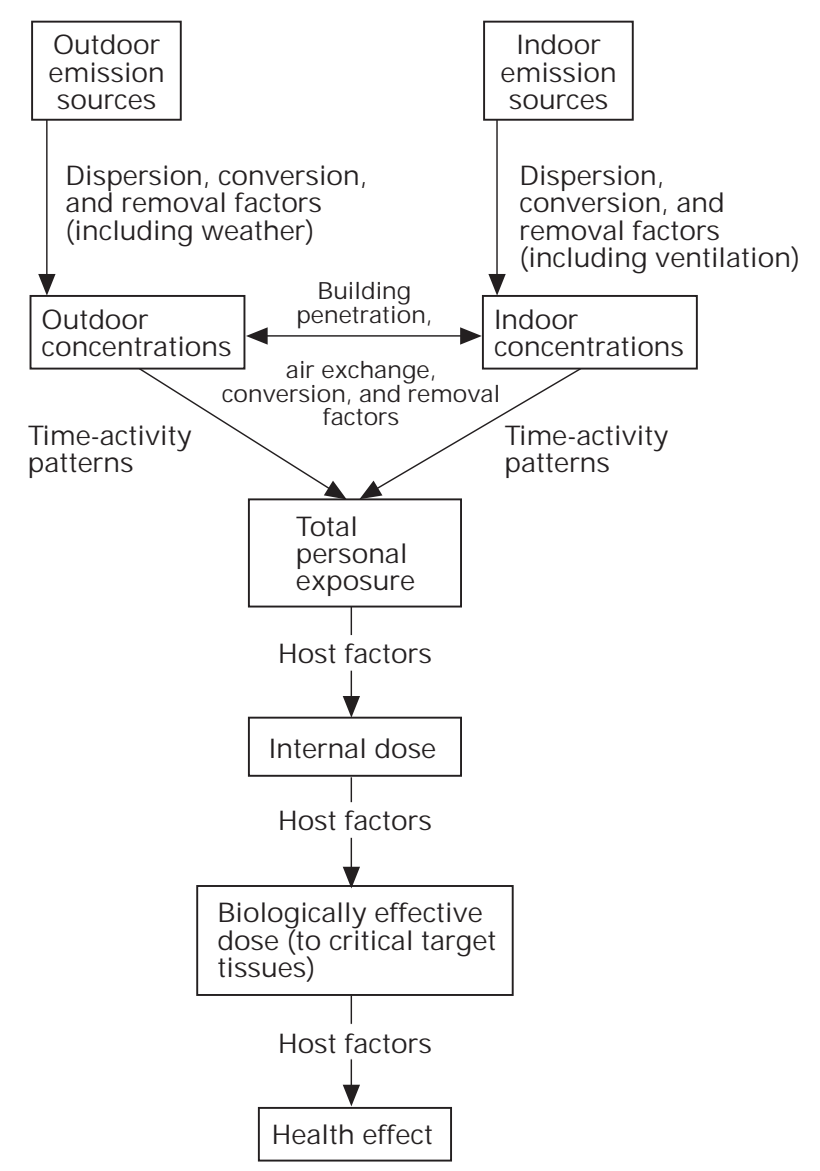

Figure 1 Framework for exposure assessment.

TOXICOLOGY OF $\mathrm{NO}_{2}$ EXPOSURE

The mechanism of $\mathrm{NO}_{2}$ toxicity is related to oxidant injury. $\mathrm{NO}_{2}$ is a strong oxidiser that initiates lipid peroxidation in cells which, in turn, results in cell damage or death. The toxicology of $\mathrm{NO}_{2}$ has been studied and the work has been summarised in several reviews. ${ }^{13-15}$ In brief, exposure to $\mathrm{NO}_{2}$ has, in animal models, multiple effects on the respiratory system. Long term exposure to high concentrations (>1000 ppb) can result in permanent damage to the epithelium in the centriacinar region of the lung and emphysematous changes. Exposure to $\mathrm{NO}_{2}$ can affect the defence mechanisms of the lung and increase susceptibility to infection. Some studies have documented alterations in the function of ciliated cells that line the airways and of alveolar macrophages (reduced mobility, phagocytic activity and killing capacity), while others investigating infectivity in kiling capacity), while others investigating infectivity in tibility to and mortality from experimental infections after exposure to $\mathrm{NO}_{2}$. These studies have limitations because the level of exposure was 1-2 orders of magnitude higher than is typically found in indoor environments.

\section{Epidemiological evidence}

\section{PREVIOUS WORK}

Early work that triggered interest in the effects of gas appliances came from M elia et al ${ }^{16}$ who studied a cohort of primary school children in England and Scotland. Controlling for social class, family size, and other factors, they reported a higher prevalence of respiratory symptoms among children from homes with a gas cooker than from homes with electric cookers. 


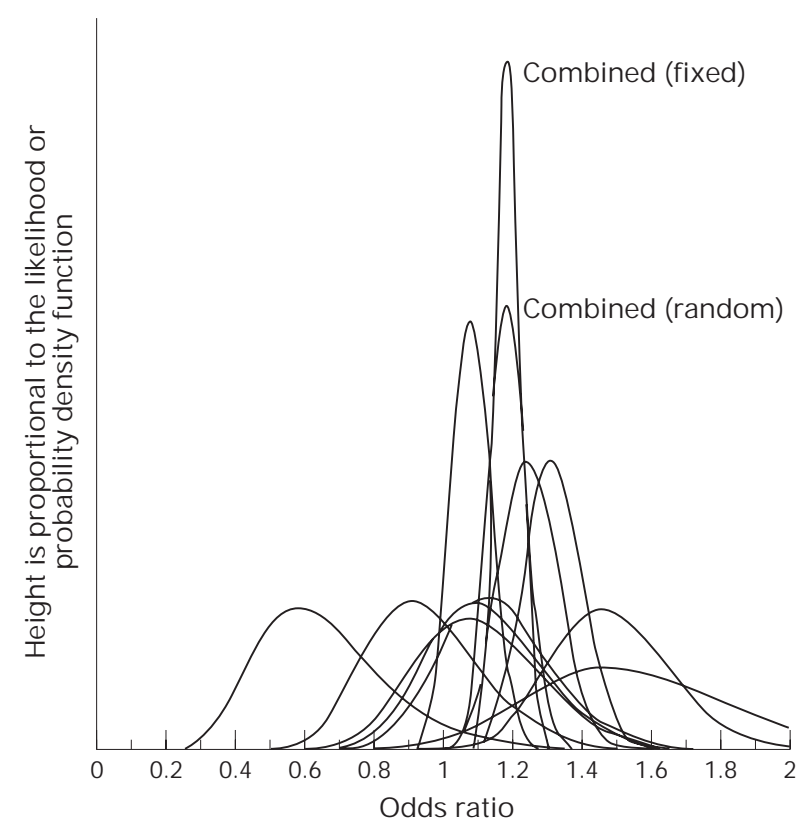

Figure 2 Meta-analysis of epidemiological studies of $30 \mu \mathrm{g} / \mathrm{m}^{3}$ increase in nitrogen dioxide exposure

$M$ any studies examining the health effects of gas appliances and exposure to $\mathrm{N}_{2}$ have subsequently been published. Initial studies focused on children as those published. Initial studies focused on children as those
believed to be at increased risk of exposure. The results helieved to be at increased risk of exposure. The results have not yielded a consistent picture of an association
between gas appliances, $\mathrm{NO}_{2}$, and respiratory health. Some studies have shown a small but significant effect, while others have shown no effect or a non-significant association. Fewer studies have been performed in adults, but they too have given conflicting results. Studies of indoor exposure offer only modest support for the hypothesis that exposure to $\mathrm{NO}_{2}$ can lead to increased frequency of respiratory illnesses and/or symptoms. $M$ ethodological limitations associated with such studies - low statistical power, exposure misclassification, confounding or effect modification by other pollutants, and insensitivity of health outcomes - could explain the inability to obtain definitive conclusions. ${ }^{13-15}$

To address the concern that low statistical power was responsible for the lack of consistent findings, in 1992 $\mathrm{H}$ asselblad et al performed a meta-analysis. ${ }^{17}$ T hey made several assumptions, adjustments, and acknowledgements in combining the studies. Firstly, the end point being measured was similar in all studies. Secondly, the $\mathrm{NO}_{2}$ exposure levels differed among studies and were indirectly assessed in some A standardincreaseo $\mathrm{m}^{3}$ (15 ppb) was used. This was the average increase in background $\mathrm{NO}_{2}$ exposure for homes with gas apbackground $\mathrm{NO}_{2}$ exposure for homes with gas ap-
pliances over those without. ${ }^{18}$ All studies were used to pliances over those without. ${ }^{18}$ All studies were used to
estimate the effect of an increase of $30 \mu \mathrm{g} / \mathrm{m}^{3}$ (15 ppb) even if they had a different exposure range. Thirdly, each study controlled for key covariates. The results were combined using four different methods with similar results and the combined analysis yielded an estimated risk ratio of $1.18(95 \% \mathrm{Cl} 1.08$ to 1.29: fig 2). Thus the combined results suggest an increase in odds of respiratory illness of about $18 \%$ in children exposed to

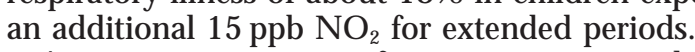

Accurate assessment of exposure is central to any epidemiological study. Studies of indoor air pollution, and of $\mathrm{NO}_{2}$ in particular, are prone to random misclassification of exposure. M isclassification of health outcome is also of concern. Lung function can be measured reliably with standard procedures in adult and older children, yet many studies use the incidence or severity of acute respiratory illness as the health outcome, not objective quantification of functional impairment Thereisno standard protocol for classi of respiratory illness, and classfication is largely of respiratory illess, and Classification is largely dependent on the physician making the diagnosis.

Samet et al published results from a large prospective study subsequent to the meta-analysis. ${ }^{1920} \mathrm{~A}$ cohort of 1205 infants was followed prospectively from birth to 18 months. Symptom diaries were used to identify outcome. $\mathrm{NO}_{2}$ concentrations in three rooms of each home were monitored with a Palmes diffusion tube for ifficant differences in the incidence or duration of respiratory illness, as reported by symptom diary, between children in homes with gas cookers and those with electric stoves. There was no consistent dose-response relationship between reports of illness and levels of $\mathrm{N} \mathrm{O}_{2}$, defined as a categorical variable ( $<20 \mathrm{ppb}, 20-40 \mathrm{ppb}$, and $>40 \mathrm{ppb}$ ). H owever, the ability of the study to detect an association study was designed on the basis of the results of a pilot study that documented a higher level of $\mathrm{N}_{2}$ exposure. For the lower range of $\mathrm{NO}_{2}$ exposure seen, the study had poor statistical power to detect an effect of $\mathrm{NO}_{2}$ exposure on respiratory illness.

$\mathrm{M}$ easurement of $\mathrm{N}_{2}$ levels with a Palmes diffusion tube was thought to represent a major improvement over reliance on surrogate information such as report of a gas appliance in the home. But a Palmes diffusion tube only provides information on average exposure for 1-2 week periods and cannot take into account intermittent peak exposures to $\mathrm{NO}_{2}$ that may have more important health effects. In animal studies short term peak exposures to $\mathrm{NO}_{2}$ had more influence on the outcome of bacterial infections in mice than did low autcome of bac used in these experiments were higher than typically documented in indoor environments (baseline $200 \mathrm{ppb}$ with peaks to $800 \mathrm{ppb}$ twice a day over a one year period). It remains possible that the short term peaks experienced indoors through intermittent use of appliances and the movement of occupants between rooms are more important than average exposures.

INTRODUCTORY ARTICLE BY JARVIS ET AL ${ }^{22}$

The study by Jarvis et $\mathrm{a}^{22}$ adds supporting evidence to the association between domestic gas appliances and respiratory health. It forces a re-examination of the population and type of exposure associated with increased risk. The study was a cross-sectional analysis of a stratified random sample of adults aged 20-44 years living in three different communities in East Anglia, UK. A mong respondents there were high prevalences of reported exposure to gas cookers $(59.4 \%)$ and open gas fires $(53.9 \%)$. These figures are consistent with previously published results. ${ }^{23}$ The investigators noted a number of important associations. Firstly, the use of gas for cooking was associated with an increased risk of respiratory symptoms in the past 12 months (table 1 ). Secondly, women who used a gas stove for cooking or who lived in homes with open gas fires had poorer lung function than those without these characteristics (table 2). Of interest is the finding that these effects differed between the sexes with an increased risk being seen only in women. Thirdly, in women exposed to gas cooking there was a trend towards increased respiratory 
Table 1 Unadjusted frequency and adjusted* odds ratio of respiratory symptoms in women who use a gas stove symptom

\begin{tabular}{|c|c|c|c|}
\hline \multirow[t]{2}{*}{ Symptom } & \multicolumn{2}{|c|}{$\%$ with symptom } & \multirow{2}{*}{$\begin{array}{l}\text { Odds ratio } \\
(95 \% \text { Cl)* }\end{array}$} \\
\hline & $\begin{array}{l}\text { Gas stove } \\
\text { non-users } \\
(n=267)\end{array}$ & $\begin{array}{l}\text { Gas stove } \\
\text { users } \\
(n=392)\end{array}$ & \\
\hline \multirow{8}{*}{$\begin{array}{l}\text { Wheezet } \\
\text { Wheeze with } \\
\text { breathlessnesst } \\
\text { Wheeze without } \\
\text { a coldt } \\
\text { Waking with chest } \\
\text { tightnesst } \\
\text { Waking with shortness } \\
\text { of breatht } \\
\text { Waking with attack } \\
\text { of coughingt } \\
\text { Athma attackt } \\
\text { Current use of asthma } \\
\text { medication ath } \\
\text { Hayfever or nasal } \\
\text { allergies }\end{array}$} & 19.8 & 31.6 & 2.07 (1.41 to 3.05 \\
\hline & 10.1 & 20.1 & 2.41 (1.51 to 3.88 \\
\hline & 10.5 & 21.9 & 2.67 (1.68 to 4.26 \\
\hline & 15.4 & 22.2 & 1.61 (1.05 to 2.46 \\
\hline & 5.2 & 11.0 & 2.32 (1.24 to 4.34 \\
\hline & $\begin{array}{r}34.4 \\
3.4\end{array}$ & $\begin{array}{r}39.3 \\
7.6\end{array}$ & $\begin{array}{l}1.22 \text { (0.64 to } 1.93 \\
2.60 \text { (1.20 to } 5.65\end{array}$ \\
\hline & 4.1 & 10.7 & 2.88 (1.46 to 5.70 \\
\hline & 28.4 & 32.1 & 1.20 (0.86 to 1.69 \\
\hline
\end{tabular}

Table 2 Adjusted odds ratios* for respiratory symptoms Adove for cooking

\begin{tabular}{|c|c|c|}
\hline \multirow[t]{2}{*}{ Symptom } & \multicolumn{2}{|l|}{ Odds ratio $(95 \% \mathrm{Cl})^{*}$} \\
\hline & $\begin{array}{l}\text { Non-atopic } \\
(\mathrm{n}=331)\end{array}$ & $\begin{array}{l}\text { Atopic } \\
(\mathrm{n}=172)\end{array}$ \\
\hline \multirow{5}{*}{$\begin{array}{l}\text { Wheezet } \\
\text { Wheeze without } \\
\text { breathlessnesst } \\
\text { wheeze without a coldt } \\
\text { Waking with chest } \\
\text { tightnesst } \\
\text { Waking with shortness } \\
\text { of breatht } \\
\text { Waking with attack } \\
\text { of coughingt }\end{array}$} & 1.94 (1.10 to 3.45$)$ & 1.71 (0.83 to 3.50$)$ \\
\hline & $\begin{array}{l}1.77(0.85 \text { to } 3.64) \\
2.18(1.09 \text { to } 4.40)\end{array}$ & $\begin{array}{l}3.27(1.34 \text { to } 7.94) \\
3.72(1.54 \text { to } 9.00)\end{array}$ \\
\hline & 1.24 (0.69 to 2.22 ) & 2.39 (1.00 to 5.72$)$ \\
\hline & 1.21 (0.49 to 2.99$)$ & 4.24 (1.25 to 14.30$)$ \\
\hline & $1.23(0.77$ to 1.95$)$ & 1.31 (0.66 to 2.57 ) \\
\hline
\end{tabular}

symptoms among atopic women compared with nonatopic women. These results suggest effect modification of the association of gas appliances and respiratory

symptoms by both sex and atopic status.
There are two possible explanations for the sex differences. Traditionally, women do most of the cooking and their increased risk may be secondary to increased exposure. $\mathrm{H}_{\text {arlos }}{ }^{12}$ studied the variation in $\mathrm{NO}_{2}$ concentration in homes with a gas cooking stove. The kitchen area was the most complex room in the house with respect to air flow patterns and $\mathrm{N}_{2}$ concentrations. C ooking activities resulted in the highest $\mathrm{N}_{2}$ exposures. If the stove convective flow loop is short-circuited within the kitchen by closing the kitchen doors, then concentrations in the kitchen can rapidly increase to high levels. Stationary monitor measurements in the kitchen can be highly variable from point to point and the variance in measurements made in the kitchen was highest of all rooms in the house. $\mathrm{H}$ arlos found occasional high concentration peaks near 1000-1500 ppb

\begin{tabular}{|llll|}
\hline Table 3 & Cook's predicted $\mathrm{NO}_{2}$ maxima (ppb) expected \\
during meal preparation periods (extreme value \\
estimates for a sample size of about 50)
\end{tabular}

(table 3). A second important finding is that a cook's maximum exposure for short averaging times (five seconds to three minutes) could not be predicted by a stationary monitor or by the cook's longer averaging time maxima.

Jarvis et al attempted to look at this question by a stratified analysis. Among women who used gas cookers, housewives and unemployed women did not have an increased risk compared with women who were emincreased risk compared with women who were em-
ployed or were students, but we do not know if the ployed or were students, but we do not know if the
latter used a gas stove and/or oven less often than the former. H ousewives and unemployed women who had an open gas fire for room heating had a reduction in forced expiratory volume in one second $\left(F E V_{1}\right)$ and the ratio of $\mathrm{FEV}_{1}$ to forced vital capacity (FVC) compared with women who had open gas fires but were or were employed. This finding suggests that parts 作 the difference between women and men may be related to a difference in exposure. Jarvis et al did not find that women who had an extractor fan had a lower risk than those who did not. This finding is not inconsistent with the hypothesised role of increased exposure (presence of a vented fan does not guarantee it is used appropriately). In a report published by the US Gas Reprearch Institute (GRI), although half the homes with Research Institute (GRI), although haf the homes with a gas stove or oven reported the presence of a vented
fan, only $10.8 \%$ of the households were thought to benefit from proper venting. ${ }^{23}$

A second explanation for the effect modification by sex may be constitutional - for example, hormonal differences. Both animal and human studies show that other environmental exposures can affect males and females differently. Exposure of rats to cigarette smoke led to a greater increase in the number of mucusproducing tracheal goblet cells in female rats than in male rats, ${ }^{2425}$ the differences being related to the oestrous cycle. ${ }^{26}$ In adolescent humans $\mathrm{G}$ old et al found a doseresponse relation between smoking and lower levels of $\mathrm{FEV}_{1} / \mathrm{FVC}$ and mid maximum expiratory flow (M M EF) ${ }^{27}$ Adolescent girls were more vulnerable than of lung function. These sex differences may relate to the calibre of the airways or to hormonal differences. Several published studies have examined controlled exposure to $\mathrm{NO}_{2}$ of both normal and asthmatic subjects. Some subjects exhibit significant increases in bronchial responsiveness after $\mathrm{NO}_{2}$ challenge but the results have been inconsistent and the response has not been related literature to suggest that inhalation of $\mathrm{NO}_{2}$ at concentrations encountered in the home environment can potentiate specific bronchial responsiveness of atopic patients with mild asthma to inhaled antigen ( $D$ pteronyssinus). ${ }^{28}$ Jarvis et al examined the interaction of atopic status with the association between domestic gas appliances and respiratory health and found that atopic women were 


\section{LEARNING POINTS}

* Epidemiological evidence suggests that there may be a modest adverse effect of exposure to domestic gas appliances on respiratory health.

* The effect in the individual of environmental pollutants is the result of a complex interaction of multiple factors and is prone to random misclassification; in epidemiological studies this can lead to underestimation of the true effect or to the conclusion that there is no effect when one exists.

* $\mathrm{NO}_{2}$ levels vary widely with time and space in homes using domestic gas appliances, and short term peak exposures to $\mathrm{NO}_{2}$, rather than average exposure levels, may determine the respiratory health effects.

* Individual susceptibility to $\mathrm{NO}_{2}$ exposure may be modified by constitutional characteristics, and risk may be increased by female sex and atopy.

* The population attributable risk fraction (PAR\%), which is a function not only of the relative risk but also of the prevalence of a particular exposure in the population, appears to be large (26-43\%) for the effect of domestic gas appliances on respiratory symptoms.

more adversely affected, but their result did not reach statistical significance.

A final point is emphasised by estimates of the population attributable risk fraction (PAR\%) presented in the paper. The estimates were made for women as this was the population found to be at increased risk. The PAR \% is the proportion of disease that can be attributed to a particular exposure, assuming there is a causative is the proportion of disease that could be prevented if the exposure of interest were eliminated. The prevalence of gas cooking stoves is $47-60 \%$ in developed countries. ${ }^{2324}$ Despite effect estimates of only modest degree, the PAR\% of exposure to gas appliances on respiratory symptoms may be large (26-43\%), secondary to a high prevalence of exposure.

\section{Conclusions}

The difficulty of studying indoor pollutants such as $\mathrm{NO}_{2}$ due to inherent problems of accurate exposure assessment may explain the inconsistent results published in the literature In addition, individual exposure is highly dependent on time-activity patterns, and peris highy dependent on timeacti dified by conD espite these limitations, the existing evidence suggests that there may be a modest effect of exposure to gas appliances on respiratory health. In future research we need to identify the pattern of exposure and the subgroups associated with increased risk.

1 G orbach SL, Bartlett J G, Blacklow N R. Infectious diseases. Philadelphia: WB Saunders, 1992

2 Buist AS, Vollmer WM. Reflections on the rise in asthma morbidity and mortality. J AM A 1990;264:1719-20.

in children? Evidence from the national study of health and growth 1973-86. BM $1990 ; 300.1306-10$.

4 Szalai A. The use of time: daily activities of urban and suburban populations

in twelve countries. The Hague, Netherlands: M outon, 1972.
Chapin FS. Human activity patterns in the city. N ew York: Wiley-

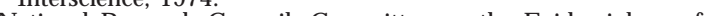

Pollutants. Epidemiology and air pollution. Washington, DC:N ationa

Academy Press, 1985. Apte M G, Dillworth JF, White PD. Indoor air pollution due to emissions from unvented gas-fired space heaters. Spengler ID F ontrol A Ssoc 1985;35:231-7. nitrogen dioxide levels inside and outside homes and the implications on health effects research. Environ Sci Technol 1979; 13:1276-80. Spengler JD, D uffy CP, Letz R, Tibbitts TW, Ferris BD. Nitrogen ambient air quality standards and health effects research. Environ $S \mathrm{~S}$ Technol 1983;17:164-8.

$10 \mathrm{H}$ atton DV. Collagen breakdown and $\mathrm{NO}_{2}$ inhalation. A rch Environ $11 \mathrm{Mizutani} T \mathrm{~L}$ ayon Aj. Clinical applications of nitric oxide Chest 1996

$2 \mathrm{H}$ arlos DP. Acute exposures to nitrogen dioxide during cooking or 13 Advisory Group on the M edical Aspects of Air Pollution Episodes. Third Report. Oxides of nitrogen. London: H M SO, 1993.

Sources of Samet JM, Utell MJ. The risk of nitrogen dioxide: what have we learned from epidemiologic and clinical studies? Toxicol Ind H ealth 1990;6

247-61.
16 M elia RJW, F lorey CV, D arby SC, Palmes ED, G oldstein BD. DifferEnviron 1978; 12:1379-81.

$17 \mathrm{H}$ asselblad V, E Eddy D M. Synthesis of environmental evidence: nitrogen dioxide epidemiology studies. I Air Waste M anag A Assc 1992:42 $\mathrm{N}$ eas $L M$, D ockery D W, Ware JH, Spengler JD, Speizer FE, F erris BD. ( Samet JM ambert WE Skipper B C Cushing AH H unt WC Youn $S A$, et al. Nitrogen dioxide and respiratory illness in children. Part I: $H$ ealth Lambert WE, Samet JM, H unt WC, Skipper BJ, Schwab M, Spengler JD. Nitrogen dioxide and respiratory illness in children. Part II: A ssesment
of exposure to nitrogen dioxide. USA: H ealth Effects Institute Report

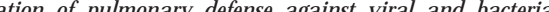
infections by acute exposures to nitrogen dioxide. Research Report N $\mathrm{O}$. 20. Cambridge, M assachusetts: H ealth Effects Institute, 1988.

symp and of domestic gas appliances. Lancet 1996;347:426-31.

$23 \mathrm{~K}$ oontz M D, M hegan $\mathrm{CL}$, N agda N $\mathrm{L}$. Distribution and use of cooking appliances that can affect indoor air quality. Topica
930013 . Chicago: G as Research Institute. 1992.

$24 \mathrm{H}$ ayashi $\mathrm{M}$, Huber GL. Quantitative differences in goblet cell in the

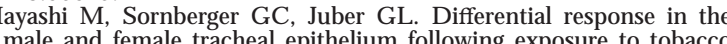
male and female tracheal epithelium following exposure to tobacco 26 Chalon j, L oew DA, Orkin LR. Tracheobronchial cytologic changes 27 Gold DR. Wenstrual cycle. J AM A 1971;218:1928-31. Effects of cigarette smoking, on lung function in adolescent boys and 28 T unnnicliffe WS, Burge PS, Ayres SG. Effect of domestic concentrations of nitrogen dioxide on airway responses to inhaled allergen in asthmatic 